\title{
¿ES REALMENTE EL INTERÉS SUPERIOR DEL NIÑO UNA NORMA DE PROCEDIMIENTO? A PROPÓSITO DE LA OBSERVACIÓN GENERAL № 14 DEL COMITÉ DE LOS DERECHOS DEL NIÑO
}

Is the Best Interest of the Child Really a Procedure Norm? Regarding General Comment No 14 of the Committee on the Rights of the Child

\author{
FRANCESCO CARRETTA MUÑOZ* \\ Pontificia Universidad Católica de Valparaíso
}

\section{RESUMEN}

En este artículo se examina el interés superior del niño y sus alcances en el proceso. Para ello, se recurre al canon propuesto por la Observación General №14 del Comité de los Derecho del Niño de Naciones Unidas. Sobre aquel documento se hacen algunas precisiones que parten por aclarar qué es lo que significa que el principio se asimile a una "norma de procedimiento". Luego, se clarifican los puntos que constituyen el canon señalado en base a algunos problemas procesales que acontecen en la justicia de familia, referidos al derecho de defensa, el derecho al recurso, la óptima valoración por parte de la autoridad de los hechos que afectan a los niños y la competencia. La novedad que ofrece este artículo es el estudio del principio general desde un prisma procesal, habida cuenta que la doctrina mayoritariamente lo trata desde un punto de vista sustantivo.

\section{PALABRAS CLAVE}

Procedimiento de familia, interés superior del niño, principio jurídico

\section{ABSTRACT}

The best interests of the child are examined as an interpretive principle and its scope in the process. For this purpose, the canon proposed by General Comment № 14 of the UN Committee on the Rights of the Child is used. On that document some clarifications are made that start by clarifying what it means that the principle is assimilated to a "rule of procedure". Then, the points that constitute the canon indicated are clarified based on some procedural problems that occur in family justice, referred to the right of defense, the right to appeal, the optimal assessment by the authority of the facts that affect children and the jurisdiction of the courts. The novelty offered by this article is the study of the general principle from a procedural prism, given that the doctrine mostly treats it from a substantive point of view.

\section{KEYWORDS}

Family procedure, Best Interest of the Child, Legal Principle

\section{Introducción ${ }^{* *}$}

Desde hace algún tiempo Naciones Unidas ha intentado fijar algunos límites al principio del interés superior del niño. Con aquel propósito el Comité de los Derechos del Niño de dicho organismo internacional dictó la Observación General №14 del 29 de mayo del año 2013 (en adelante OG). En dicho instrumento el Comité consignó una serie de parámetros, entre ellos, uno que puede parecer peculiar y que origina esta indagación. El documento señala

\footnotetext{
* Profesor agregado de Derecho Procesal Civil de la Pontificia Universidad Católica de Valparaíso. Dirección postal: Facultad de Derecho, Pontificia Universidad Católica de Valparaíso, Casilla 4055, Valparaíso, Chile. Dirección electrónica: francesco.carretta@pucv.cl. Este trabajo es actualmente parte de una investigación patrocinada por Conicyt a través del proyecto Fondecyt regular $\mathrm{N}^{\circ} 1190329$ del que el autor es el investigador responsable.

** Lista de abreviaturas: OG: Observación General №14 del 29 de mayo del año 2013 del Comité de los Derechos del Niño de Naciones Unidas; NNA: Niños, Niñas y Adolescentes; UNICEF: Fondo de las Naciones Unidas para la Infancia; CDN: Convención de Derechos del Niño; LTF: Ley N 19.968 que crea los Tribunales de Familia de 25 de agosto de 2004.
} 
expresamente que el interés superior del niño es al mismo tiempo "una norma de procedimiento".

En este trabajo se pretende demostrar que, por una parte, dicha frase que busca asimilar dos categorías jurídicas distintas no es acertada, $y$, por la otra, que no obstante dicho inconveniente, es posible desentrañar su significado mediante dos actividades. La lectura completa y atenta del texto de la OG y la sistematización de los parámetros que esta contiene.

A partir de ahí, también se intentará demostrar que la mencionada frase obedece a que dicho organismo pretendió estrechar, delinear y dirigir los contornos del interés superior del niño hacia un área que hasta el momento de su redacción no se había cubierto: el derecho procesal. Con tal fin, ha fijado un canon hermenéutico cuyo rango de aplicación se extiende a algunos factores que inciden en su tramitación. Estos serán ordenados en este trabajo en base a dos premisas, el ejercicio de los derechos del niño para ante la autoridad, por un lado y, la óptima determinación por parte de esta, de los hechos que le afectan, por el otro.

Con esto, ha de descartarse la idea -evocada por el lenguaje de la OG - de que el principio general del interés superior del niño pueda transformarse en una norma procesal autónoma que permite una aplicación directa, independiente o incluso contraria a las reglas establecidas por la ley de un ordenamiento particular para la sustanciación de un procedimiento, como es posible que lo hayan entendido algunos tribunales chilenos, según se examinará al final de esta obra.

En síntesis, es posible que cuando el Comité de Ginebra utiliza la locución "norma de procedimiento", se trate de una licencia retórica que se esgrime en el excesivo afán de explicar que las normas procesales pueden, a la luz del principio general, ser interpretadas dentro del ámbito de la justicia de familia a través de los lineamientos específicos que se examinarán a continuación.

\section{Normas procesales y principios jurídicos: ¿qué quiso decir el Comité de Ginebra?}

La OG establece que: "El concepto de interés superior del niño es en sí mismo una norma de procedimiento"1. Si esta frase se lee con detención, el lector podrá notar en ella un contenido que puede resultar paradojal ${ }^{2}$. Evoca el mismo grado de indeterminación que se le atribuye a la directriz, en circunstancias que debería delimitarla ${ }^{3}$. Es cierto que el lenguaje jurídico es un terreno ambiguo cuyas palabras poseen una textura abierta ${ }^{4}$, sobre todo si se está intentado fijar los contornos de un principio ${ }^{5}$. Pero en este caso, se trata de una frase que produce una vaguedad semántica que expande su significado a contrasentidos que alcanzan un nivel superior del acostumbrado y tolerable 6 . En algún punto, parece decir que tal principio general se trata de una regla procesal sin contenido, lo que permitiría una aplicación directa en la tramitación de un procedimiento, con independencia de las leyes vigentes de un ordenamiento, tal como se pudo hacer percibido por los sentenciadores en los fallos que se analizarán en el capítulo final de este estudio. Pero, como se examinará a continuación, dicha suposición es incorrecta, porque una regla adjetiva y un principio son dos institutos diferentes ${ }^{7}$.

En efecto, lo primero que ha de decirse, como lo han notado algunos autores, es que los principios jurídicos presentan una notoria ambigüedad ${ }^{8}$. Además, no están supeditados a esquematizaciones y su ubiquidad hace imposible que se pueda ejercer sobre ellos una labor sistemática como aquella que se puede ejercer sobre las normas adjetivas que se encuentran

\footnotetext{
${ }^{1}$ COMITÉ DE LOS DERECHOS DEL NIÑO (2013), p. 19.

${ }^{2}$ La importancia del instrumento en análisis es que, sin rodeos, puede considerarse, al igual que todas las observaciones dictadas por el Comité, como una fuente auténtica y fidedigna de interpretación de la Convención. NIETO (2011), pp. 155-190.

${ }^{3}$ KOHN (2008), p. 339; GARRIDO (2013), p. 119; RAVELLAT y PINOCHET (2015), p. 904.

${ }^{4}$ ENDICOTT (2006), pp. 65-73, capítulo 2.

${ }^{5}$ HART (2012), pp. $124-126$

${ }^{6}$ MARMOR (2014), pp. 101-104.

${ }^{7}$ PECZENIK (1992), p. 332.

${ }^{8}$ LUZZATI (2012), pp. 4-5; SCHAUER (1991), pp. 12-15; PECZENIK (1992), p. 332.
} 
bien definidas. En ese sentido las reglas procedimentales fijan y ordenan el rito de un proceso y poseen hipótesis concretas que definen sus consecuencias.

Desde una óptica valorativa los principios ostentan un notable contrafuerte ético puesto que a ellos subyacen valores sociales ${ }^{9}$. En cambio, las reglas procedimentales no tienen un considerable sustrato axiológico ${ }^{10}$.

Desde un punto de vista funcional, de acuerdo con la dogmática, los principios tienen varios roles, $y$, aunque no existe acuerdo en cuáles son y cuál es su contenido ${ }^{11}$, hay consenso que los principios sirven como reglas interpretativas ${ }^{12}, y$, en menor medida, que bajo determinadas condiciones podrían llenar vacíos legislativos ${ }^{13}$. En cuanto a las normas procesales, aun cuando el proceso posee parámetros propios, no hay duda de que sirve al derecho de fondo. Es por esa razón que la doctrina lo clasifica como meramente instrumental ${ }^{14}$ y puede entenderse que está subordinado al derecho sustantivo ${ }^{15}$.

En este orden de ideas, las normas procesales son reglas obligatorias que enseñan como se debe proceder para obtener justicia ${ }^{16}$. Entonces, cuando se hace referencia a una cuestión procesal, por encima de todas las precisiones técnicas, se quiere expresar el uso contingente de los mecanismos por los que el derecho sustantivo se encausa para encontrar una solución equitativa. Este derecho de fondo si no encontrase un medio donde se pudiesen focalizar los conflictos que intenta solucionar, no tendría un sentido práctico ${ }^{17}$, y no cumpliría su misión de la tutela jurídica de los intereses de un niño, en relación con la temática del presente trabajo ${ }^{18}$.

A partir de esa comprensión básica es útil entender que la norma procesal es aquella que, si se sigue el esquema elaborado por Cohen, comprende la distinción entre reglas de conducta y reglas de decisión, siendo estas últimas las que pueden entenderse como "procesales". Las primeras, se mueven en el territorio del derecho de fondo, se dirigen al público en general y buscan ofrecer una guía para la conducta de aquel público. Las segundas, que transitan en el proceso, están dirigidas a los funcionarios encargados de la dirección de este y les proporcionan directrices para sus decisiones ${ }^{19}$. Estas deben coordinarse debido a su función (¿para qué sirven?) o su estructura (¿cómo operan?), puesto que buscan sistematizar legalmente conductas humanas que luego convergen en deberes, facultades y cargas que se desarrollan en el devenir del proceso ${ }^{20}$. Nada tiene que ver aquello con los alcances y estructura de un principio jurídico que, como se señaló, en este caso, busca precisar el sentido y alcance de la norma adjetiva que regula la manera de proceder de tales imperativos.

Por lo tanto, si lo que pretendió el Comité era delimitar los contornos del principio, logró lo contario: a la generalidad le sumó confusión. Este error puede cristalizar en las consecuencias prácticas de un mal entendimiento de la cuestión que podrían reflejarse en que el encargado de aplicarlas pretenda alterar o crear normas del procedimiento praeter legem, con los riesgos que ello conlleva para la seguridad jurídica. Algo de esto puede notarse en las sentencias que se revisan al final.

En suma, ¿qué quiso decir el Comité ginebrino? Al parecer ha querido expresar que el interés superior del niño sirve para interpretar las normas procesales que convergen en los procedimientos que buscan la tutela de la infancia, cuyo fundamento emana del conjunto de

\footnotetext{
${ }^{9}$ MACCORMICK (2007), pp. 28-30.

10 Esta afirmación se hace tomando en consideración la notable tesis que postula el formalismo valorativo del proceso. Véase ÁLVARO (2007), pp. 35-39.

${ }^{11}$ GUASTINI (2013), pp. 34-36.

12 BELADIEZ (2010), pp. 165-166; ALPA (2006), pp. 17-18.

${ }^{13}$ GUASP y ARAGONESE (1998), pp. 72-75; RAVETLLAT y PINOCHET (2015), p. 923.

14 TOMASSEO (2000), p. 13; PROTO (1996), p. 34; LIEBMAN (2012), p. 39.

15 SOLUM (2004).

${ }^{16}$ CALAMANDREI (2006), p. 27

${ }^{17} \mathrm{RICCl}$ (1998), p. 32.

${ }^{18}$ El derecho sustantivo que el proceso encausa le da el calificativo correspondiente. En este caso se habla de proceso de familia e infancia que es parte del proceso civil. TOMASSEO (2000), pp. 10-11.

19 DAN-COHEN (1983), p. 630.

${ }^{20}$ MANDRIOLI (2007), pp. 8-9.
} 
normas protectoras de la infancia ${ }^{21}$, en un rango de acción que se extiende a lo menos a los factores se analizarán en los capítulos siguientes ${ }^{22}$.

\section{Catálogo de aspectos que conforman el canon interpretativo propuesto por la Observación General}

Puede ocurrir que el lector se confunda con los puntos que serán tratados a continuación ya que no parecen presentar un orden consecutivo lógico (secuencial) en su estructura. Es por ello por lo que se pide que se tenga en cuenta que en este trabajo se está realizando una descripción de los parámetros que han sido tratados en la OG con un orden similar al expuesto en dicho documento, a los que se les ha adicionado originalmente una sistematización general en base a dos premisas, según fue dicho en la introducción. Luego, tampoco se crea que por esta razón solo se consignará a continuación, sin más, una mera descripción de lo que el Comité a escrito en la OG.

En cada apartado se han propuesto notas críticas y reflexivas sobre los tópicos de fondo que contiene cada uno de los parámetros que serán citados a continuación. Estos guardan relación con el derecho a la defensa, el derecho del niño a ser escuchado, el derecho al recurso y algunos deberes procesales que las autoridades judiciales asumen con los niños, niñas y adolescentes (en adelante: NNA).

\section{El ejercicio de los derechos de los niños, niñas y adolescentes para ante la autoridad}

Las pautas que se mencionan en este y los demás apartados de este trabajo, no son las únicas que se deben tomar en consideración para darle una aplicación procesal al principio. Desde luego que hay otras que el intérprete aplicará conforme a los criterios que le parezcan más adecuados. Los parámetros que se describirán no obstan, por ejemplo, la aplicación del elemento histórico, sistemático, gramatical y lógico de interpretación. No crea tampoco el lector que estos son los únicos derechos procesales cubiertos por la Convención. Sucede que el Comité se ha centrado en los tópicos que reciben una gran afluencia en la protección de la infancia, pero queda claro que hay otros tales como el derecho de trabar incidentes, deducir contiendas de competencia o ser asistidos por un intérprete en los juicios.

Se insiste en que la útil labor que ha hecho el Comité ginebrino es abarcar un área que hasta ahora no se había cubierto por el principio del interés superior del niño, cual es el área procesal y, para no caer en meras generalizaciones, ha señalado los puntos a seguir.

\section{El derecho a defensa}

Respecto del derecho a defensa, la OG da por supuesto que es necesaria la existencia de una institución que se encargue de la protección general y particular de los derechos de la infancia para asegurar la efectiva tutela de los derechos de la niñez. Esta institución debe ser un estamento independiente con poderes suficientes y que conceda garantías efectivas y específicas para ejercer la tutela de los derechos de los NNA en instancias gubernamentales y las que no tienen ese carácter ${ }^{23}$. Por lo tanto, desde un nivel supra constitucional, el principio cumple su función orientadora si se establece en el ordenamiento al que se dirige la implementación de un ente con todas esas características.

El 22 de enero de 2018 entró en vigencia en Chile la ley N² 21.067 que crea la Defensoría de la Niñez. Su denominación es un tanto engañosa, pues induce a pensar que se está frente a un organismo ampliamente estructurado como la defensoría penal o laboral, en circunstancias

\footnotetext{
${ }^{21}$ BELVEDERE et al. (1994), pp. 339-340.

${ }^{22}$ COMITÉ DE LOS DERECHOS DEL NIÑO (2013), pp. 18-19.

${ }^{23}$ Esta figura cumple una función similar al Ombudsman que, según da cuenta un acucioso estudio elaborado por Ravetllat se encuentra presente desde antaño en Europa y América Latina y exhibe una serie de variantes. Véase RAVETLLAT (2017). 
que se trata en esencia únicamente de un defensor que es asesorado por un consejo consultivo que extiende su competencia a todo el territorio nacional.

Según los objetivos generales definidos por la ley, su principal función es:

desarrollar un diagnóstico de la situación de los derechos de los niños, niñas y adolescentes; y de la institucionalidad a nivel nacional, de forma de observar cuáles son los problemas, los avances y los obstáculos del tema, coordinando la institucionalidad pública en la defensa de los niños ${ }^{24}$.

Si bien la figura del defensor de la infancia es un aporte al sistema jurídico, la ley que lo regula cuenta con algunas deficiencias. Ello, por cuanto su actuación se circunscribe principalmente a fiscalizar a los órganos de la administración del Estado que tengan por objeto la promoción o protección de los derechos de los niños ${ }^{25}$. Queda fuera, por ende, el ámbito corporativo privado que es donde precisamente, según ha señalado uno de los miembros del Comité de la Responsabilidad Social Corporativa y Derechos del Niño de UNICEF, la infancia continua ausente en la mayoría de las políticas y estrategias de responsabilidad empresarial ${ }^{26}$. En ese orden de ideas se puede entender que esta normativa no siguió la observación realizada por Naciones Unidas el año 2015 que se refiere a esta problemática ${ }^{27}$.

Esto es especialmente importante porque la responsabilidad de la empresa hacia los NNA es amplia y no se agota en lo que parece evidente. Esto es, la acción directa que estas podrían producir en su perjuicio, tales como el trabajo infantil o no contar con guarderías en sus establecimientos. También, han de considerarse otros perjuicios de carácter indirecto, desde el impacto que sus productos producen hacia ellos, como que den a sus trabajadores las facilidades para que estos ejerzan una crianza integral. Esto último, merece jornadas laborales que permitan que aquella aspiración se haga realidad y salarios justos.

Frente a la ausencia de un ente fiscalizador eficiente y directo, que pudo haber sido la Defensoría, todas esas áreas quedan desprovistas de mecanismos efectivos de tutela en este ámbito. En Chile, a diferencia de otros países, ni siquiera tiene la posibilidad de brindar asesoramiento a dichas instituciones para la interpretación y aplicación de la Convención, como tampoco fomentar en ellas su aplicación efectiva ${ }^{28}$. Lo anterior, en consonancia con las recomendaciones que el Comité estableció dentro de las atribuciones que deberían poseer los organismos de defensa de los derechos humanos ${ }^{29}$. Esto sería ideal, pero en el caso chileno es una cuestión de lege ferenda.

\section{El derecho del niño a expresar su propia opinión}

Este derecho es en realidad una herramienta a través de la cual, mediante las expresiones de los niños - que no se restringen a las de tipo verbal, sino que se extienden también a las no verbales - se puede indagar con mayor precisión las cuestiones que les afectan ${ }^{30}$. De este modo, quien decida sobre los derechos de un NNA debe tener en cuenta la posibilidad de escucharlo en las etapas que sean admitidas en los procedimientos correspondientes. Estos pueden gestarse en sede judicial, pero también en otros modelos e instancias de participación extrajudiciales ${ }^{31}$. Este derecho también se encuentra tratado en la Observación General $N^{\circ} 20$ con un enfoque exclusivo a la adolescencia. En ese sentido se destaca la participación de los

\footnotetext{
${ }^{24}$ Según la declaración que aparece en la página web del servicio. Disponible en: https://bit.ly/2SE3PzX [visitada el 16 de junio de 2020].

25 RAVETLLAT (2017), p. 295.

${ }^{26}$ Véase información disponible en https://bit.ly/3uDORJe [visitada el 16 de junio de 2020].

27 COMITÉ DE LOS DERECHOS DEL NIÑO (2015), pp. 41-42.

${ }^{28}$ MIRANDA (2015), pp. 14-17.

${ }^{29}$ COMITÉ DE LOS DERECHOS DEL NIÑO (2002), p. 5.

${ }^{30}$ En efecto, incluso se ha podido observar el lenguaje de lactantes a través de las gesticulaciones que ejecutan con sus dedos. Véase FARKAS (2008), pp. 108.

${ }^{31}$ PARKES (2013), pp. 15-16.
} 
adolescentes como un instrumento de negociación que ese grupo etario puede usar para aumentar su participación ciudadana en los diversos ámbitos de la esfera política y social ${ }^{32}$.

Cualquiera sea el caso, se trata de un trabajo arduo para quién lo realiza, ya que debe valorar si el NNA está en condiciones de ser escuchado. Para ello, de acuerdo con las exigencias que se desprenden del artículo 12 de la Convención de Derechos del Niño (en adelante CDN), debe cerciorarse si el NNA tiene suficiente juicio, para luego ponderar su opinión en función de su edad y madurez ${ }^{33}$. Por lo tanto, dicha tarea requiere de capacitación y de comprensión que se trata de una labor que es más horizontal que vertical, ya que la autoridad encargada de llevar a cabo el trámite asume una función constructiva y dialéctica en la solución del problema que aqueja al NNA y no tan impositiva ${ }^{34}$.

Zanjado esto, ha de garantizarse la posibilidad de que el niño pueda expresarse, sin perjuicio que esto ocurra efectivamente o no, ya que no puede establecerse como una obligación llevar a efecto la gestión en todos los $\operatorname{casos}^{35}$. Además, debido a circunstancias aleatorias no es posible recoger en todas las situaciones los dichos de un NNA y tampoco puede este ser obligado a opinar. En este sentido, de acuerdo con el artículo 12 de la CDN, escuchar al niño es una facultad del juez, por lo cual este no puede estar obligado a escucharlo si estima, como se dijo antes, que el niño no tiene el suficiente juicio o madurez ${ }^{36}$.

Ahora bien, cabe preguntarse ¿de qué manera actúa en esto el interés superior del niño desde un vértice procesal? Lo primero que se debe examinar es, desde un punto de vista general, si las legislaciones que ratificaron la CDN tienen prevista la posibilidad de escuchar a un niño en sede judicial. Si está prevista, valga lo dicho en el párrafo precedente. Si no, deberá instaurarse un dispositivo idóneo para ejecutar el trámite, dado que la CDN siempre puja en favor de la introducción de reformas legales en los Estados suscriptores del pacto. En la legislación en que exista un vacío sobre el presente punto, este debe ser integrado por el señalado artículo 12 de la CDN. Es decir, deben abrirse espacios de entrevistas para los NNA antes de tomar cualquier decisión que los afecte. Lo contrario podría permitir la revisión de la resolución a la luz del Tratado, lo que, por cierto, depende de la fuerza que cada ordenamiento le dé a los mismos conforme a su derecho interno ${ }^{37}$.

También debe tenerse presente el Protocolo Facultativo de la Convención sobre los Derechos del Niño relativo a un procedimiento de comunicaciones. En él se establece como guía el principio del interés superior del niño y además el derecho del niño a ser escuchado, debido a que en el procedimiento que contiene deben tenerse en cuenta los derechos y opiniones del niño, y dar a esas opiniones el debido peso, de acuerdo con la edad y madurez de este ${ }^{38}$.

En virtud de este instrumento los NNA en su propio nombre o representados que crean ser víctimas de vulneración de sus derechos pueden pedirle al Comité que se pronuncie formalmente al respecto. También, puede hacer la denuncia cualquier persona que observe alguna perturbación a los derechos de los niños establecidos no solo en la Convención, sino que además en el Protocolo facultativo de la Convención relativo a la venta de niños, la prostitución infantil y la utilización de niños en la pornografía y el Protocolo facultativo de la Convención relativo a la participación de niños en los conflictos armados.

El Comité puede dirigir al Estado parte una solicitud para que adopte medidas urgentes antes de ver la cuestión de fondo. Incluso, dicho organismo puede actuar de oficio cumplidos

\footnotetext{
32 COMITÉ DE LOS DERECHOS DEL NIÑO (2016), p. 8.

${ }^{33}$ SÁNCHEZ (2011), p. 60.

${ }^{34}$ VARGAS y CORREA (2011), p. 187.

${ }^{35}$ Sobre varios aspectos de este derecho y la forma como debe ejercerse en el procedimiento, en particular sobre cómo debe lleva rse a efecto la entrevista de los niños en las salas Gesell, la Corte Suprema dictó un auto acordado (Acta 37-2014).

${ }^{36}$ Cierta polémica se produce sobre este tópico desde que la Corte Suprema ha comenzado a anular, mediante el arbitrio de la casación, los litigios donde el niño no es oído. El máximo tribunal, para sustentar la utilización del mencionado recurso, trasunta el sentido de lo "esencial", desde aquella significación que proviene de la relevancia del derecho, a aquella que se refiere a los trámites que son vitales para el devenir de un juicio. Esta interpretación no es correcta, ya que no existe obligación para el juez de escuchar al niño de acuerdo con la Convención y la ley. Véase CARRETTA (2018a).

${ }^{37}$ ALDUNATE (2010), p. 186.

${ }^{38}$ ASAMBLEA GENERAL DE NACIONES UNIDAS (2011), p. 3.
} 
algunos requisitos. Esto se puede hacer con total independencia de las acciones que el perjudicado haya entablado en el Estado parte, siempre que haya agotado los recursos internos y haya transcurrido menos de un año desde ese hecho.

Mediante este mecanismo, bastante similar a un recurso jurisdiccional, el Comité se ve en la obligación de evacuar un dictamen que señala recomendaciones sobre la transgresión acometida.

Ciertamente, se está en presencia de un dispositivo procesal idóneo para resguardar todas las garantías de los NNA. Lamentablemente, como señala un estudio exhaustivo sobre este asunto, este protocolo aun no logra desplegar todo su potencial en favor de la tutela de los derechos de la infancia ${ }^{39}$.

Finalmente, aunque es un tema que no está expresado dentro de los puntos que aborda la Observación en comento y supera con creces los objetivos que se han planteado en este estudio, no puede dejarse de mencionar la siguiente pregunta: ¿si ha de escucharse a los NNA en sede judicial, como ha de gestarse por ellos la interposición de las acciones que les competen? Esta es una duda que se responde a la luz de los vértices que conlleva el instituto procesal de la legitimación activa, lo que consecuencialmente también acarrea una interrogante sobre la capacidad procesal. En otras palabras, la posibilidad autónoma de un NNA de ejercer por sí mismo una acción y actuar en juicio sin la autorización y representación de otra persona. Sin perjuicio del patrocinio letrado que óptimamente podría ejercer una entidad dedicada a los derechos de la infancia. Pues bien, en Chile, a diferencia de otras latitudes ${ }^{40}$, esta es una cuestión de lege ferenda. En primer lugar, la legitimación activa de los NNA requiere necesariamente la interposición de acciones por personas mayores de edad que actúan en su representación. Luego, los NNA tiene la capacidad para ser parte en el proceso, no así la capacidad procesal que se asemeja a la capacidad de ejercicio civil que es la necesaria para ejercitar derechos sin el ministerio o autorización de otros, según el artículo 1445 del Código Civil. De esta manera, menos poseen la facultad de pedirle al juez que se haga cargo obligatoriamente de sus solicitudes personales en el devenir del proceso. Se insiste que en Chile esta es una cuestión que merece mayor discusión teórica en miras a una adecuada regulación legal.

\section{La posibilidad de recurrir las resoluciones que afectan a los NNA}

Los teóricos discuten si existe en materia civil el derecho al recurso y cuáles son sus alcances ${ }^{41}$. Una parte de la doctrina estima que no es viable porque, entre otras razones, no está explícitamente establecido así ni en la ley ni en la Constitución ${ }^{42}$. Dichos autores se refieren sin duda a las materias civiles patrimoniales, ya que no puede extrapolarse a ellas lo que sucede en materia penal, donde el derecho al recurso sí es ampliamente aceptado, debido a las consecuencias que para la libertad de una persona implica un fallo en esa materia. De este modo, en el ámbito penal no hay dudas de su existencia, ya que tanto la Convención Americana sobre Derechos Humanos (art. 8), como el Pacto Internacional de Derechos Civiles y Políticos (art. 14.5) lo señalan expresamente. Además, estos tratados han sido incorporados al ordenamiento jurídico chileno a través del artículo 5o de la Constitución, lo que conforma el denominado bloque de constitucionalidad, y por tanto parte del debido proceso penal chileno ${ }^{43}$.

\footnotetext{
${ }^{39}$ RAVETLLAT Y CONTRERAS (2019), p. 225.

${ }^{40}$ En el Convenio Europeo sobre el Ejercicio de los Derechos de los Niños de Estrasburgo de 1996 el NNA es considerado como un sujeto procesal, con un catálogo de facultades procesales en virtud de las cuales pueden entenderse como un litigante plenamente capaz, una verdadera parte en el proceso. Véase MAGNO (2001), pp. 55-76, capítulo 4.4.

${ }^{41}$ PALOMO (2010), p. 467; NUÑEZ (2008), pp. 219-221.

42 DUCE et al. (2015). "El derecho a un recurso y el proceso civil". Disponible en: https://bit.ly/3yP5svb [visitado el 20 de octubre 2019].De acuerdo con estos autores, este derecho no está establecido en la Convención Americana sobre Derechos Humanos ni en el Pacto Internacional sobre Derechos Civiles y Políticos. Señalan además que la jurisprudencia internacional se ha referido únicamente a casos penales. En suma, la posibilidad de recurrir sobre temas patrimoniales no sería un derecho humano.

43 DEL RÍO (2012), p. 249.
} 
Evidentemente, los temas de familia son de carácter extrapatrimonial y, por ende, más cercanos a lo que acontece en el orden punitivo. En consecuencia, se puede decir con un buen grado de certeza que en la justicia de familia sí existe el derecho al recurso. Se encuentra implícitamente en el artículo 3ㅇ de la CDN y a partir de ahí como una de las garantías procesales que conlleva el principio rector, tal como lo señala la OG en comento ${ }^{44}$. Al ser la CDN un tratado sobre derechos fundamentales, se entiende incorporado en el ordenamiento jurídico chileno. Sin embargo, a diferencia del proceso penal, donde se tratan de delinear los contornos operativos del imperativo por la doctrina que aún no se pone de acuerdo en ellos ${ }^{45}$, en el proceso de familia se puede recurrir a estándares más delimitados de acuerdo los lineamientos que ha establecido el Comité y que se examinan a continuación.

En primer lugar, la OG es categórica en resaltar que en todo procedimiento deben darse a conocer los mecanismos de impugnación al niño o a su representante legal ${ }^{46}$. La OG expone que el ente revisor siempre debe verificar: (i) si se considera que se han incumplido las garantías procesales; (ii) si los hechos materia del asunto que le afecta no son exactos; y, (iii) si no se ha llevado a cabo adecuadamente la evaluación del interés superior del niño o se ha concedido demasiada importancia a consideraciones contrapuestas ${ }^{47}$. Esto está en consonancia con todos demás parámetros que se examinan en este artículo.

Es relevante destacar que según se desprende del instrumento en análisis puede entenderse que todos estos factores deben examinarse copulativamente por el órgano revisor, sin que necesariamente se haya solicitado su revisión por el recurrente ${ }^{48}$. Se trataría de una excepción a la congruencia procesal como proyección del principio dispositivo en materia de recursos. Sin embargo, al igual que todo medio de impugnación, debe tenerse como requisito indispensable para su interposición el agravio como una causal genérica de procedencia ${ }^{49}$. Para el caso, consiste en el perjuicio material o moral que pueda sufrir un NNA en cualquiera de las facetas que constituyen su integridad con una decisión formal de la autoridad judicial o administrativa si es el caso. Si bien para la teoría general del proceso esto resulta evidente, en materia de derechos de la infancia puede, en ocasiones, no resultar así. El detrimento asociado a la dictación de una resolución tiene ciertas particularidades y por lo tanto es necesario hacer algunas precisiones al respecto.

Puede suceder que quienes están llamados a la tutela de los derechos de la infancia intenten recursos jurisdiccionales que sean innecesarios y hasta perniciosos. Tales son los casos donde si bien existe algún perjuicio que faculta su interposición, se trata de situaciones que podrían considerarse de baja magnitud y en las que pueda ser posible encontrar alivio en el mero transcurso del tiempo o en otras instancias. Se debe tener en cuenta que, tratándose de las materias extrapatrimoniales en referencia, la presentación de un recurso puede reportar mayores inconvenientes que en otras competencias. Significa el transcurso de un lapso mayor de tiempo al previsto para la tramitación ordinaria de un litigio que deja latente el problema que le subyace con el consiguiente estrés para los involucrados, principalmente los NNA. Así, es posible visualizar también daños colaterales a miembros del entorno familiar que quizá no tienen una relación directa con el pleito y, si el NNA vive regularmente en dicho entorno, puede directa o indirectamente crearse un problema circular que puede terminar perjudicándolo aún más.

Además, si el solo hecho de que un NNA se enfrente al sistema de justicia es de por sí vulnerador, una prolongación indebida de ese estatus de inseguridad y, quizá la posibilidad de

\footnotetext{
${ }^{44}$ COMITÉ DE LOS DERECHOS DEL NIÑO (2013), p. 21.

${ }^{45}$ DEL RÍO (2012), p. 251.

${ }^{46}$ COMITÉ DE LOS DERECHOS DEL NIÑO (2013), p. 21.

${ }^{47}$ COMITÉ DE LOS DERECHOS DEL NIÑO (2013), p. 21.

${ }^{48}$ COMITÉ DE LOS DERECHOS DEL NIÑO (2013), p. 21.

${ }^{49}$ MOSQUERA y MATURANA (2010), pp. 25-26.
} 
que el NNA concurra en más de una oportunidad al tribunal, dando por cierto que en la justicia de familia acontece la victimización segundaria, la situación se torna mucho más grave ${ }^{50}$.

La sentencia, independiente de su resultado, siempre otorga un alivio en la tramitación de un proceso y en las circunstancias materiales que viven los sujetos que intervienen en él. Con su dictación salen de la incerteza que en ocasiones es una verdadera penumbra que implica la espera de un resultado incierto. De esta manera, los justiciables y las entidades encargadas de la tutela de los derechos de la infancia deben tener una mayor previsión a la hora de decidir recurrir en contra de una decisión jurisdiccional. Para ello se debe valorar la magnitud del agravio y si es posible que la dinámica vulneradora encuentre un remedio en el transcurso del tiempo, en el seno protector de una familia o de la o las personas que se harán cargo de la situación y/o en la intervención de las entidades que pueden encargarse de monitorear y ejecutar programas de protección. Der ser así, debería evitarse seguir adelante con instancias revisoras. Sobre todo, si se tiene en cuenta que estas carecen, por lo menos en el sistema chileno, de inmediación. Las Cortes toman un conocimiento lejano de las circunstancias que rodean la dinámica que llevó la situación litigiosa y siempre a través de un intermediario que será el relator o las partes que cuentan al tribunal superior los antecedentes. Por cierto, no se está exponiendo aquí la formula simplista por la cual por el solo hecho de no asistir a la producción y rendición de las pruebas el tribunal de segunda instancia queda vedado de revisar todos los aspectos que constituyen la valoración de la prueba que efectúa el tribunal de primera instancia ${ }^{51}$.

Desde luego que el tribunal revisor debe fiscalizar la coherencia en el razonamiento probatorio, como también debe verificar el buen uso de los parámetros de la sana crítica, tal como se explora brevemente en el capítulo siguiente. Solo se están visualizando, para la prognosis propuesta, los riesgos insalvables que posee el hecho que hay cierto grado de probabilidad que las Cortes tomen conocimiento de los hechos desde una óptica sesgada, sobre todo en aquellos casos en que solo una de las partes concurre a hacer sus alegatos.

En síntesis, el interés superior del niño actúa en esta materia cuando el operador tiene en cuenta: (i) que es indubitado que los NNA tiene el derecho al recurso lo que implica que siempre podrán por sí o por sus representantes impugnar aquellas resoluciones adoptadas por la autoridad que puedan afectar alguna de las facetas de su vida; (ii) a su vez, que este derecho para el caso de los NNA se ve reforzado por el hecho de que el ente revisor debe ir más allá de lo que específicamente se les pueda solicitar en el escrito de impugnación en aquello que pueda favorecer y fortalecer sus garantías procesales, y (iii) finalmente, que todo lo dicho debe ser matizado por la visualización de la ponderación entre las posibles mayores consecuencias que puede acarrear la interposición de un recurso y sus ventajas.

\section{La óptima determinación por parte de la autoridad de los hechos que afectan a los NNA}

\section{Premisa}

Este tópico, según se infiere de la lectura de la OG, está constituido por la inmejorable apreciación de las circunstancias que podrían dar lugar a estudiar la aplicación de una medida de protección en favor de los NNA por parte del encargado de tutelar jurídicamente sus derechos $^{52}$. Para que aquello se haga realidad el ente protector deberá tener en cuenta dos vértices de referencia que se despliegan sobre los hechos que constituyen la problemática que

\footnotetext{
${ }^{50}$ Las dudas que se plantean en este punto son porque no hay investigaciones que revelen claramente los efectos de la victimización segundaria en la justicia de familia, a diferencia de lo que ocurre en sede penal. Estudios de derecho comparado revelan que hay niños que se sienten aliviados al contar sus problemas a los jueces y sentirse partes de la decisión, al contrario de lo que comúnmente se piensa en torno a lo disruptivo que puede resultarle concurrir a un tribunal. Véase GUTIÉRREZ et al. (2009) y SAVOURY (2013).

${ }^{51}$ NIEVA (2010), pp. 33-34.

52 COMITÉ DE LOS DERECHOS DEL NIÑO (2013), pp. 19-20.
} 
puede afectar a los NNA. Estos, dicen relación con (i) la pesquisa de los hechos -a los que subyace la situación compleja - y su análisis preliminar, por una parte; y, (ii) la manera como se debe argumentar en torno a las ideas y conclusiones que se pueden extraer de ellos, por la otra.

\section{La pesquisa de los hechos y su adecuado análisis}

En cuanto a este punto, se debe partir de la base que los hechos que inciden en la cuestión que afecta a los NNA se extraen de la observación de los lugares donde estos habitualmente se desarrollan, y, primordialmente, a través del testimonio y los antecedentes de las personas que conforman su entorno familiar, social, educacional y de salud. Lo primero que el Comité de Ginebra requiere en este punto es que los profesionales encargados de evaluar la información recabada a partir de dichos antecedentes deban estar perfectamente capacitados, aspecto en el que insiste repetidamente en el documento. Sobre esto, hay que tener en cuenta que los profesionales encargados de esta labor en sede jurisdiccional en los diversos ordenamientos occidentales son generalmente dos, el juez y un profesional del área sicosocial. Ambos poseen competencias y conocimientos que apuntan en direcciones diversas. Es por ello por lo que a continuación se intentará precisar esta relación y como debiera actuar, ya que en la OG no hay una adecuada diferenciación y aclaración de esto.

El texto de la OG establece que la determinación de los hechos por los que se deduce el interés superior de un niño requiere un acabado conocimiento psicosocial por parte del encargado de recabarlo ${ }^{53}$. En este punto parece que el Comité confunde dos elementos que son autónomos: la apreciación de los hechos para solucionar jurídicamente el asunto - una cuestión jurídica de carácter probatoria que compete a los operadores jurídicos, primordialmente al juez-; con la opinión técnica que puede existir sobre los mismos hechos y la visualización, en base a las mismas circunstancias, de lo que será mejor a futuro para el NNA. Este último aspecto es de dominio de los profesionales que ejercen sus oficios dentro del área de las ciencias sociales y de la salud. Para llegar a formarse una opinión recurren a las herramientas de su arte, en el caso de los trabajadores sociales, las visitas domiciliarias, por ejemplo, en el caso de los sicólogos, a test proyectivos, en determinadas ocasiones. Los jueces por su parte recurrirán a la interpretación de la ley, y, desde ahí, a los argumentos necesarios para que razonadamente se puedan encuadrar los hechos al derecho, para luego otorgarles los efectos que este prescriba para solucionar la situación particular. Desde luego que, en la justicia de familia, aunque los primeros poseen naturalmente una mayor experticia sobre los temas de su competencia, los segundos igualmente deben tener un conocimiento general sobre estas temáticas. A la inversa, los consejeros técnicos también poseen un conocimiento general del derecho de la infancia y la familia.

Sin embrago, se debe tener en cuenta que, aunque pareciere serlo, no se asume un trabajo completamente mancomunado en esto. Es decir, no puede el juez descansar en las opiniones de los técnicos, sin representarse si lo que estos dicen es o no es acertado, dentro del contexto del caso. Es factible que la experiencia del juez, su conocimiento científico o el sentido de las normas involucradas en la solución del asunto apunten hacia un lugar distinto al de los expertos $^{54}$. En definitiva, debe prevalecer la opinión de quien finalmente tomará la decisión.

En Chile, desde el año 2005 los tribunales de familia cuentan con un Consejo Técnico conformado fundamentalmente por asistentes sociales y psicólogos. En ciertas causas, dichos profesionales deben emitir obligatoriamente sus opiniones, si bien estas no son vinculantes para el juez. Dichas opiniones no son un elemento de convicción que se deba ponderar como un medio de prueba tradicional. Son recomendaciones sobre la manera de proceder en un caso $u$ otro.

\footnotetext{
${ }^{53}$ COMITÉ DE LOS DERECHOS DEL NIÑO (2013), p. 20.

${ }^{54}$ Es por ello por lo que en algunos países que han suscrito el tratado, como en España, las opiniones de los técnicos no son vinculantes. ABEL (2019), p. 33.
} 
Sobre esto, un reclamo ocasional de los operadores se da porque, en ciertos casos, el juez le confiere demasiada preminencia a la opinión del consejero técnico, lo que conduce a pensar que en el fondo es aquel quién decide. Sucede que, en la práctica, aunque está reglamentado en el artículo 64 de la LTF que las partes pueden emitir sus observaciones sobre lo que el consejero dijo, esto no ocurre por regla general. Así, en varias ocasiones de la opinión del consejero se pasa directamente al veredicto que, si es coincidente con lo que el profesional dijo, lo que posiblemente sucede en la mayoría de las veces, queda la sensación que dicha opinión ocupa un lugar preminente en la decisión del caso, en circunstancias que no debería ser así. La opinión técnica de acuerdo con el artículo 5o de la ley recién citada constituye una instancia de asesoramiento para el juez, no una prueba. Es por ello por lo que no puede, en teoría, producir algún grado de convicción para la decisión del asunto. Se trata solo de un consejo que se puede tomar o no. En este sentido en ciertas ocasiones las Cortes han llamado la atención a algunos jueces por tener únicamente en cuenta en sus resoluciones la opinión del consejero.

También se reprocha, tanto por los intervinientes como por la misma judicatura, la falta de una capacitación permanente y sistemática en materias de infancia para los jueces ${ }^{55}$. La Academia Judicial - el organismo encargado de la formación continua de jueces y juezasimparte algunos cursos anualmente en materia de infancia. Sin embargo, estos cursos no son obligatorios, son de corta duración y no están enfocados a un adiestramiento continuo en determinadas materias. No existen niveles progresivos de instrucción en ellos.

La forma como los hechos han de verterse argumentativamente en la decisión

Una vez recopilada la información necesaria para clarificar las posibles situaciones que pueden estar afectando a los NNA, debe ponerse especial atención a la manera como ella será expresada en la resolución que decide el destino de los derechos de los NNA. En otras palabras, los datos recopilados conforme a lo que se ha dicho hasta aquí, han de hilvanarse con la argumentación jurídica donde se han de plasmar todos los aspectos - fácticos, técnicos y jurídicos-que razonadamente se deben tener en consideración para adoptar una decisión que afectará los derechos de los niños. En buenas cuentas, la decisión debe estar suficientemente fundamentada.

El estándar exigido por el Comité es alto, pues en la OG se plantea en términos estrictos esta exigencia. En ella establece que la decisión debe ser "fundamentada, justificada y explicada" y con mayor énfasis si en esta se difiere de la opinión del NNA o no se atiende a su interés superior ${ }^{56}$. Esto, aunque parece obvio, el Comité estimó necesario remarcarlo probablemente por la constante crítica ${ }^{57}$ que se ha generado desde antaño por la amplitud e indeterminación del concepto ${ }^{58}$. En efecto, un razonamiento escueto en esta materia ha levantado recelos por la doctrina, ya que de esa manera se estima que el principio del interés superior del niño se tiende a transformar en el lugar común de los sentimientos paternalistas de los jueces ${ }^{59}$. Así, dicho principio a veces se ha tornado en la muletilla habitual que los encargados de decidir utilizan cuando quieren cubrir jurídicamente una resolución basada en el mero sentido común o en su particular sentido de justicia parcelado a una suerte de empatía con quién se considera débilio.

A su vez, también puede ocurrir que para encubrir la falta de fundamentación o una débil fundamentación se acuda al prestigio jurídico que concede la locución "interés superior del niño". En ese caso, se trataría de un uso retórico que únicamente se sustenta en la autoridad

\footnotetext{
${ }^{55}$ CARRETTA (2018b), pp. 136-138.

${ }^{56}$ COMITÉ DE LOS DERECHOS DEL NIÑO (2013), pp. 20-21.

57 KOHM (2008), p. 337.

58 FREEMAN (2007), pp. 1-2.

${ }^{59}$ CILLERO (2001), p. 9; GONZALEZ (2006), p. 104

${ }^{60}$ RAVETLLAT y PINOCHET (2015), pp. 904-905.
} 
del concepto, ya que, a través de aquel ingenio, no se le da ningún contenido. En la OG se señala que no es posible fundamentar la sentencia únicamente en dicho principio, sin explicitar la forma como se desarrolla en el caso ${ }^{61}$. La manera correcta de hacerlo en el sentido expuesto es revistiendo al concepto de los derechos particulares que corresponden a los NNA de acuerdo con todos los estatutos jurídicos protectores que les asistan y especialmente conforme a los derechos establecidos en la Convención en correlación a los hechos que hayan sido determinados conforme a las pruebas del proceso. En ese orden de ideas, no se encuentra justificada una resolución si solo se menciona la locución interés superior del niño sin señalar cuales imperativos jurídicos se han considerado en correlación con las cuestiones fácticas que pueden ser tomadas en consideración para solucionar el asunto.

Por lo demás, una controversia de derecho de familia e infancia generalmente involucra más de un imperativo jurídico. Un litigio sobre custodia, por ejemplo, parte desde el artículo tercero que consagra el principio. Luego, pasa por el derecho que posee el NNA a ser oído que está señalado en el artículo 12 de la CDN que para el caso será escuchar y tomar en cuenta lo que este diga sobre la cuestión que le afecta. A su vez, se deberá considerar que, según el artículo 27, el niño tiene derecho a un nivel de vida adecuado para su desarrollo físico, mental, espiritual, moral y social y, conforme a ello, debe explorarse en qué lugar o con quién se aseguran de mejor manera dichos valores. Esto debe ser matizado con lo prescrito por el artículo 18 en cuanto a que ambos padres tienen obligaciones comunes en lo que respecta a la crianza y desarrollo de sus hijos y conforme al artículo 5 estos además tienen el derecho a darles dirección y orientación. Sin perjuicio de las normas protectoras que establezca un ordenamiento jurídico en particular.

Finalmente, no puede pasarse por alto un aspecto, ya que ha sido tocado en el desarrollo de las ideas que se han plasmado en este capítulo y el anterior, pero que tampoco puede ser abordado en toda su extensión dada su envergadura. Se trata de la circunstancia de que actualmente rige para la valoración de los hechos en la justicia de familia el sistema de la sana crítica que es hacia donde apunta la justicia civil en general. Se debe tener presente que dicho sistema implica en una buena parte una labor argumentativa por parte del juez, cuando en las conclusiones que plasma en su sentencia, no puede contradecir los principios de la lógica, los conocimientos científicamente afianzados y en especial a las máximas de la experiencia ${ }^{62}$.

Las tres directrices presentan dificultades en todas las competencias jurisdiccionales y han motivado la atención de la doctrina, pero se hace énfasis en la última porque se ha dicho que a partir de su mal entendimiento puede tomar un lugar prominente el arbitrio judicial ${ }^{63}$.

Esto, en la justicia de familia puede ser especialmente sensible, teniendo en cuenta la vulnerabilidad de los sujetos de tutela. Su erróneo entendimiento sucede, por ejemplo, cuando estas se confunden con prejuicios o generalizaciones basadas en el sentido común ${ }^{64}$, en circunstancias que las máximas de la experiencia, receptadas por el ordenamiento jurídico chileno ${ }^{65}$, son:

definiciones o juicios hipotéticos de contenido general, desligados de los hechos concretos que se juzgan en el proceso, procedentes de la experiencia, pero independientes de los casos particulares de cuya observación se han inducido y que, por encima de esos casos, pretenden tener validez para otros nuevos ${ }^{66}$.

\footnotetext{
${ }^{61}$ COMITÉ DE LOS DERECHOS DEL NIÑO (2013), p. 4.

${ }^{62}$ TARUFFO (2002), pp. 209-210; CARBONELL (2018), p. 41; STEIN (1999), p. 23.

${ }^{63}$ ALISTE (2011), p. 346.

${ }^{64}$ TARUFFO (2002), pp. 209-210.

${ }^{65}$ BENFELD (2013), p. 570.

${ }^{66}$ STEIN (1999), p. 23.
} 
Una investigación cualitativa sobre cómo piensan los jueces a partir de un estudio empírico que se gestó en base a las entrevistas realizadas a algunos magistrados chilenos sugiere que habría ciertas confusiones sobre este aspecto -el uso de las máximas - por parte de ellos ${ }^{67}$.

Un ejemplo de lo que se viene diciendo puede encontrarse en una sentencia que se pronunció sobre una causa de alimentos:

que, a los gastos anteriores, deben sumarse aquellos que la experiencia indica que existen, en personas que tienen un buen pasar o bien pertenecen a un segmento de la población con mayores ingresos que es la posición de la familia (....), en concepto de esta sentenciadora, y que dada la envergadura y el volumen de la vivienda, que habitan, así como el barrio en que se encuentra emplazada (Santa María de Manquehue) hacen indispensable incurrir en ellos (así como también, lo deberá necesariamente, hacer el demandado y su conviviente). Gastos que no se pueden incluir dentro del ítem imprevistos, porque requieren de inversiones mayores que aquellas que se podrían incluir dentro de aquél informado por \$80.000. mensuales, suma por la que podría hacerse a una limpieza de vidrios mensual de la propiedad que cuenta con dos pisos (...) o bien, una limpieza de alfombras, o bien, una reparación de un refrigerador o la visita de un gásfiter ${ }^{68}$.

Si se observa lo dicho en el fallo en realidad la sentenciadora no está valorando una máxima de la experiencia, sino que está concluyendo desde sus propias circunstancias una realidad social y desde allí está conjeturando una serie de gastos a los que atribuye un valor. Eso en realidad es un prejuicio.

Una de las causas que pueden explicar el fenómeno acontecido en los razonamientos vertidos en la sentencia se da por la peculiaridad en la justicia de familia de que puede gestarse un cruce entre el asunto que el juez está resolviendo en base a la máxima, con lo que algunas veces debe resolver en su vida diaria. Puede haber en esto una especie de sesgo de corroboración. En efecto, a menos que se trate de una persona aislada de la sociedad, el juez asume una serie de roles familiares dentro de esta, donde sin duda tiene conflictos. En ocasiones estos problemas son similares a aquellos que en el uso de su ministerio le tocará resolver respecto a otras personas. Es dable pensar que el juez de una manera consciente o no, se reflejará en los pormenores del caso sometido a su conocimiento jurisdiccional y desde ahí, más que crear una máxima basada en un conocimiento general apartado de los hechos de la causa, como los definió Stein, lo hará desde su propia experiencia, lo que puede ocasionar una equivocación que puede dar paso a la arbitrariedad ${ }^{69}$.

Esto confiere probabilidades ciertas a las incorrecciones que se están aludiendo aquí. Entonces, dada la importancia de este asunto, se ha de considerar que aplicar y argumentar adecuadamente sobre todos los patrones de la sana crítica, en especial sobre las máximas de la experiencia, es el lugar donde se debe dirigir el intérprete cuando toma el prisma del interés superior del niño desde un punto de vista adjetivo.

\section{El eco del principio en la jurisprudencia chilena}

Un reflejo de los problemas que puede acarrear verter equivocadamente el principio general en normas procesales, a parte de los reseñados a lo largo de este estudio, se pueden encontrar en al menos cinco sentencias dictadas por Cortes de Apelaciones. Estas fueron pronunciadas en causas donde se demandó el cuidado personal de un hijo, por lo que para efectos de su competencia relativa siguen la regla general. Deben presentarse en el territorio que sirve de asiento al tribunal donde el demandado tiene su domicilio. Recuérdese que los tribunales de familia son tribunales especiales y por expresa disposición del artículo 182 del Código Orgánico de Tribunales en ellos no es admisible la prórroga de la competencia. Sin embargo, como se consigna en la doctrina contenida en uno de esos fallos que se transcribe a

${ }^{67}$ COLOMA Y AGÜERO (2014).

${ }^{68}$ Cuarto Juzgado de Familia de Santiago, Rit № 6051-2006, de 20 de noviembre de 2009.

${ }^{69}$ MUÑOZ (2011), pp. 1-38. Sobre el significado de los sesgos cognitivos, véase TVERSKY y KAHNEMAN (1974), p. 1130 
continuación, aquella norma procesal no se aplica debido al interés superior del niño. Nótese que, según en el mismo aparece, esta doctrina ya es un precedente:

jurisprudencia reciente de esta Corte (Roles 557-2018 y 210-2020), sostiene que el conocimiento de este tipo de acciones ha de radicarse en aquel tribunal correspondiente al domicilio del niño, niña o adolescente. Ello en consonancia con lo dispuesto en el artículo 16 de la Ley 19.968 que establece el principio Ilamado "Interés superior del niño, niña o adolescente", pues no resulta congruente, ni con el citado principio ni con la garantía fundamental del debido proceso, que para resolver sobre sus derechos y, especialmente, para ser oídos por el juez o jueza, ellos tengan que ser trasladados de una ciudad a otra, con todo lo que eso implica desde el punto de vista sicológico, familiar y económico ${ }^{70}$

Para analizar esta situación es ilustrativo hacerlo sobre la base de un caso. Los fallos tenidos a la vista se refieren asuntos similares por lo que se tomarán los hechos contenidos en uno de ellos como muestra ${ }^{71}$. Este, se dicta en un proceso cuyo libelo de demanda debía presentarse en el domicilio del demandado, la ciudad de Ovalle. Pues bien, se presentó en el domicilio de la parte demandante, Valparaíso, y en mérito de ello el tribunal a quo procedió rechazarla habida cuenta de que conforme a la regla de competencia la demanda debía presentarse en Ovalle. Se alzó el actor en contra de la resolución arguyendo el interés superior del niño como motivo jurídico principal de su presentación, estimando que en virtud de aquel es posible prorrogar la competencia en estos casos. El fundamento de hecho se centró en que la niña respecto de la cual se solicitaba el cuidado personal vivía junto a su abuela, la demandante, en la ciudad de Valparaíso. En esas circunstancias concurrir a un tribunal lejano a su residencia le resultaba un gravamen para sus intereses, dada la dificultad de producir el material probatorio -el traslado de la prueba testimonial-, y ejercer su derecho a ser escuchado en un lugar diverso a su domicilio. La Corte acoge su pretensión en base a dichas alegaciones.

Hay que partir de la base que la situación descrita no es la de común ocurrencia. Una demanda de cuidado personal suele ser presentada por el padre o madre no custodio, por lo que la mayoría de las veces este tipo de juicios se tramita en el juzgado del domicilio del NNA.

Ahora bien, volviendo al caso en estudio, sucede que, a primera vista, se observa que la causa de pedir de la reclamación del demandante tiene sentido. Suena como protectora de los derechos del niño, en tanto facilita que este no se desplace de un lugar a otro. Pero, una mirada un poco más abstracta denota otros detalles que deben tomarse en consideración.

¿Qué derecho específico se intenta proteger en el caso particular? Lo cierto es que permanecen indemnes la integridad física o síquica de la niña con la interposición de la acción en el lugar que corresponde. El trayecto entre ambos puntos es de 365 kilómetros. Es su representante la que debe asumir los costos que esto conlleva. Que, tampoco son tales, puesto que, si no posee recursos suficientes, hay convenios entre las diversas Corporaciones de Asistencia Judicial por la que puede ser asesorada a distancia y representada por dicho organismo local. Sin contar que estos inconvenientes también buscan ser mitigados a través de los exhortos.

No obstante, en apoyo de la tesis esgrimida por la Corte podría decirse que, si la parte no cuenta con el material probatorio en el lugar de su residencia que para el caso es la ciudad de

\footnotetext{
70 Corte de Apelaciones de Concepción, Rol № 73-2020, de 5 de junio de 2020. En el mismo sentido: Corte de Apelaciones de Coyhaique, Rol № 8-2019, de 22 de marzo de 2019; Corte de Apelaciones de Valparaíso, Rol № 118-2019, de 18 de febrero de 2019; Corte de Apelaciones de Concepción, Rol № 609-2019, de 5 de septiembre de 2019. En los fallos que se citan a continuación también se permite la prórroga de la competencia en los tribunales de familia, pero no se alude al interés superior del niño como argumento, sino que lo dispuesto en el artículo 60 inciso tercero de la Ley № 19.968, de 2004: Corte de Apelaciones de Valdivia, Rol № 74-2019, de 22 de abril de 2019; Corte de Apelaciones de Santiago, Rol № 139-2019 de 4 de febrero de 2019; Corte de Apelaciones de Santiago, Rol № 1345-2017, de 22 de mayo de 2017; Corte de Apelaciones de Santiago, Rol № 1188-2017, de 24 de mayo de 2017; Corte de Apelaciones de Valdivia, Rol № 196-2013, de 19 de diciembre de 2013; Corte de Apelaciones de Valparaíso, Rol № 7362013, de 9 de diciembre de 2013, Corte de Apelaciones de Valparaíso, Rol № 707-2012, de 8 de noviembre de 2012.

${ }^{71}$ Corte de Apelaciones de Valparaíso, Rol № 802-2015, de 29 de octubre de 2015.
} 
Valparaíso, la inmediación es la que en el caso puede resultar dañada si el pleito se tramita en Ovalle. También es posible que se dificulte el derecho del niño a ser oído, si este no tiene residencia en el lugar del juicio. Pero, esta no es una contrariedad que pueda solucionar la judicatura, es un problema, si es que lo es, de los parámetros jurídicos que sostienen el sistema normativo continental en que el ordenamiento chileno se encuentra inmerso que debe encontrar, a la luz de la Constitución, una solución dentro del marco legal, en una reforma de ley. Aunque este es un tema amplio que se aparta de los fines de este estudio, el binomio que debería operar en esta situación es que frente a una norma expresa que vaya en un sentido, no es posible por la directriz general, torcerlo en el sentido completamente inverso ${ }^{72}$.

Como se ha intentado demostrar en esta obra, le interés superior del niño sirve para interpretar la norma adjetiva y a lo sumo, podría obrar a falta de ley, si se estima que esta opción es posible. Entonces, en último caso la pregunta que cabría hacerse aquí es si existe un vacío legislativo. Una laguna se forma cuando un ordenamiento jurídico no contiene una ley que otorgue solución a un problema ${ }^{73}$. En este caso existe una ley, el artículo 134 del Código Orgánico de Tribunales que contiene una respuesta a la situación que, por lo demás, se ha venido aplicando desde hace bastante tiempo en la judicatura de familia.

Siguiendo las ideas de Bulygin es probable que los jueces en estos casos hayan montado un orden jerárquico de normas y decidido no aplicar en el caso la norma menos importante. Con esto, han optado por la derogación parcial de las normas en conflicto. Pero se trata esta de "una actividad típicamente legislativa que la doctrina tradicional atribuye con exclusividad a los legisladores" ${ }^{\prime \prime 7}$. No a los jueces.

Con mayor énfasis, se puede entender que en las sentencias que contienen una ratio similar se ha actuado contra legem, lo que a su vez conduce a una paradoja. Es un contrasentido que por una parte el principio del interés superior del niño otorgue ventajas interpretativas para la aplicación de legislación, y, por la otra, atente contra ella y fisure la seguridad jurídica que resguarda.

\section{Conclusiones}

A juzgar por la ingente labor que efectúa Naciones Unidas a través de la OG en comento se puede suponer que los intentos de distintos actores para precisar el concepto desde el derecho sustantivo y el derecho internacional habidos hasta ahora, no habían sido suficientes para ceñir sus márgenes en todas las esferas posibles de actuación. Una de ellas era el derecho procesal a cuyo estudio se abocó dicho organismo internacional con la redacción del mencionado informe. Es probable que con ese fin se precipitó en mencionar que el principio es a su vez una norma de procedimiento. Por las razones argumentadas en este artículo, ello no puede ser así, ni menos debe pensarse que al juez a partir de la impronta jurídica del principio le está autorizada su actuación al margen de la legislación o en base a su sentido común.

Ahora bien, más allá de dichas imprecisiones gramaticales y el malentendido que puede acarrear expresar que el interés superior del niño es al mismo tiempo una norma de procedimiento, tómese aquella afirmación y el intento de aclararla en este estudio, como una excusa para profundizar en la labor mayormente provechosa que ha hecho el Comité de Derechos del Niño. Este organismo ha delimitado los difusos contornos del principio general desde una óptica procedimental. Lo ha hecho creando pautas interpretativas que se extiende a los siguientes factores: la manera como ha de entenderse el derecho de defensa, el derecho a ser oído y el derecho al recurso de los NNA; y, la forma como el ente de tutela debe pesquisar los hechos y analizarlos, para poder argumentar adecuadamente en su decisión en torno al principio. A partir de ellos el intérprete puede encontrar una perspectiva de análisis que le

\footnotetext{
72 Sobre esto véase CORDERO (2009), pp. 11-49.

${ }^{73}$ Sobre el extenso tema de las lagunas en el derecho véase: ATRIA et al. (2005).

${ }^{74}$ ATRIA et al. (2005), p. 44.
} 
permita solucionar problemas que surgen sobre estos tópicos que son recurrentes en la justicia de familia. Desde luego que hay otros y lo que el Comité ha querido decir es que sobre aquellos debe ejercerse una labor hermenéutica que vaya más allá de la mera mención del principio como la única cobertura jurídica que justifique una decisión. Con esto el Comité de Ginebra ha precisado además que las normas procesales han de ser interpretadas y esto puede ser hecho a la luz del interés superior del niño, con un menor riesgo de caer en generalizaciones, tautologías o el mero paternalismo jurídico con el que se suele dar contenido a dicho principio general.

A pesar de que el interés superior del niño seguirá siendo lo que es, un concepto jurídico indeterminado, los lineamientos que el Comité ha ideado, revisten el concepto de una inusitada vitalidad práctica, lo sacan de una aletargada abstracción y llevan hacia sectores más operativos.

\section{BIBLIOGRAFÍA CITADA}

Abel LluCh, XAVIeR (2019): La prueba en los procesos de familia (Madrid, Wolters Kluwer).

ALDUNATE, EdUARDO (2010): "La posición de los tratados internacionales en el sistema de fuentes del ordenamiento jurídico chileno a la luz del derecho positivo", en: Revista lus et Praxis (Vol. 16, № 2), pp. 185-210.

Aliste SANTOS, TOMÁS JAVIER (2011): La motivación de las resoluciones judiciales (Barcelona, Marcial Pons).

ALPA, GUIDO (2006): I principi generali, 2ª edición (Milano, Giuffrè Editore).

Álvaro De Oliveira, CARlos Alberto (2007): Del formalismo valorativo en el proceso civil (Lima, Palestra Editores).

Asamblea General De NACIONES UnIDAS (2011): "Protocolo Facultativo de la Convención sobre los Derechos del Niño relativo a un procedimiento de comunicaciones, A/RES/66/138". Disponible en: https://bit.ly/34wEqLI [visitado el 21 de mayo de 2021].

AtRIA, FERnANDo (2005): "La casación como problema”, en: Revista de Derecho de la Universidad Adolfo Ibáñez (№ 2), pp. 249-351.

Atria, Fernando; Bulygin, Eugenio; Moreno, José Juan; Navarro, Pablo; Rodríguez, Jorge y Ruiz MANERO, JUAN (2005): Las lagunas en el derecho. Una controversia sobre el derecho y la función judicial (Barcelona, Marcial Pons).

BAZÁN, Víctor (2014): "Amicus curiae, justicia constitucional y fortalecimiento cualitativo del debate jurisdiccional", en: Revista Derecho de Estado (№ 33), pp. 3-34.

Beladiez Rojo, Margarita (2010): Los principios jurídicos, 2a edición (Pamplona, Thomson Reuters).

BelVedere, ANDREA; GUASTINI, RICCARDO Y ZeNo, VINCENZO (1994): Glossario (Milano, Giuffrè).

Benfeld, Johann (2013): "Los orígenes del concepto de sana crítica", en: Revista de Estudios Históricos Jurídicos (№ 35), pp. 569-585.

CalamandReI, PIero (2006): Proceso y democracia (Lima, Ara Editores).

CARBonelL, FlaVia (2018): "Sana crítica y razonamiento judicial”, en: Benfeld, Johann y Larroucau, Jorge (Coords.), La sana crítica bajo sospecha (Valparaíso, Ediciones Universitarias de Valparaíso), pp. 35-48.

Carretta, Francesco (2018A): “El derecho a ser oído en la justicia de familia: la esencialidad del derecho versus la esencialidad del trámite de la audiencia confidencial", en: Revista Chilena de Derecho (Vol. 45, № 2), pp. 407-426. 
(2018B): "Luces y sombras sobre las salas Gesell en la justicia de familia chilena", en: Revista GES (Vol. 9, № 1), pp. 118-142.

Cillero BRUÑol, Miguel (2001): “El interés superior del niño en el marco de la convención internacional sobre los derechos del niño", en: Derechos de la Niñez y la Adolescencia (Costa Rica, UNICEF). Disponible en: https://uni.cf/3vDqScB [visitado el 18 de octubre 2019].

Coloma Correa, Rodrigo y Agüero SAN JuAn, Claudio (2014): "Fragmento de un imaginario judicial de la sana crítica", en: Revista lus et Praxis (№ 2), pp. 375-414.

COMIté De Los DeREChOS Del NiÑo (2002): “Observación General № 2. El papel de las instituciones nacionales independientes de derechos humanos en la promoción y protección de los derechos del niño, CRC//CG/2002/2 (15 de noviembre de 2002)". Disponible en: https://uni.cf/3idze6S [visitado el 21 de mayo de 2021].

(2007): “Observación General № 10 sobre los derechos del niño en la justicia de menores, CRC/C/GC/10". Disponible en: https://uni.cf/3idze6S [visitado el 21 de mayo de 2021].

(2009): "Observación general $\mathrm{N}^{\circ} 12$ sobre el derecho del niño a ser escuchado, CRC/C/GC/12". Disponible en: https://uni.cf/3idze6S [visitado el 21 de mayo de 2021].

(2013): "Observación general $N^{\circ} 14$ sobre el derecho del niño a que su interés superior sea una consideración primordial, CRC/C/GC/14". Disponible en: https://uni.cf/3idze6S [visitado el 21 de mayo de 2021].

(2015): "Observaciones finales sobre los informes periódicos cuarto y quinto combinados de Chile, CRC/C/CHL/CO/ (30 de octubre de 2015)". Disponible en: https://uni.cf/3idze6S [visitado el 21 de mayo de 2021].

(2016): “Observación general $N^{\circ} 20$ sobre la efectividad de los derechos del niño durante la adolescencia, $\mathrm{CRC} / \mathrm{C} / \mathrm{GC} / 20$ ". Disponible en: https://uni.cf/3idze6S [visitado el 21 de mayo de 2021].

CORDERO, EDUARDO (2009): "Los principios y reglas que estructuran el ordenamiento jurídico chileno", en: Revista lus et Praxis (Vol.15, № 2), pp. 11-49.

DAN-COHEN, MeIR (1983): "Decisions rules and conduct rules: on acoustic separation in criminal law”, en: Harvard Law Review (Vol. 97, № 625), pp. 625-678.

Del Rio Ferretti, Carlos (2012): "Estudio sobre el derecho al recurso", en: Revista de Estudios Constitucionales (№ 1), pp. 245-288.

ENDICOTT, TIMOTHY (2006): La vaguedad en el derecho (Madrid, Editorial Dykinson).

FARKAS, CHAMARRITA (2008): “Comunicación Gestual en la Infancia Temprana: Una Revisión de su Desarrollo, Relación con el Lenguaje e Implicancias de su Intervención”, en: Psykhe (Vol. 16, № 2), pp. 107-115.

FRANK, JEROME (2012): Derecho e incertidumbre, 4a edición (México D. F., Editorial Fontamara).

Freeman, Michael (2007): "The best interests of the child" (Leiden, Martinus Nijhoff Publishers).

GarRido Alvarez, Ricardo (2013): “El interés superior del niño y el razonamiento jurídico", en: Anuario de filosofía y teoría del derecho (№ 7), pp. 115-147.

Gonzalez Contro, Mónica (2006): "Paternalismo jurídico y derechos del niño", en Revista Isonomía (№ 25), pp. 101-135.

GREeVEN, Nel (2017): Filiación. Derechos humanos fundamentales y problemas de su actual normativa (Santiago, Editorial Librotecnia). 
GuASP, JaIME y ARAgoneSE, Pedro (1998): Derecho procesal civil, 4ạ edición (Pamplona, Editorial Civitas).

GUASTINI, RICCARDO (2013): Distinguendo ancora (Madrid, Marcial Pons).

Gutiérrez de Piñeres Botero, Carolina; Coronel, Elisa y Andrés Perez, Carlos (2009): "Revisión teórica del concepto de victimización secundaria”, en: Revista Liber (Vol. 15, № 1), pp. 49-58.

HART, HERBERT (2012): The concept of law, 3a edición (Oxford, Oxford University Press).

InStITUTO NACIONAL De Estadísticas (2017): "Informe anual sobre la Justicia". Disponible en: https://bit.ly/3uCYfLq [visitado el 22 de octubre 2019].

KOHM, LYNNE (2008): "Tracing the Foundations of the Best Interests of the Child Standard in American Jurisprudence", en: Journal of Law and Family Studies (Vol. 10), pp. 337-375.

LieBMAN, ENRICO (2012): Manuale di diritto processuale civile, 8ª edición (Milano, Giuffrè Editore).

LUZZATI, CLAUDIO (2012): Principi e principi. La genericità nel diritto (Giappichelli Editore).

MACCORMICK, NEIL (2007): Intitutions of law (Oxford, Oxford University Press).

MAGNO, GIUSEPPE (2001): II minore come soggetto processuale, commento alla convenzione europea sull'esercizio dei diritti dei Fanciulli (Milano, Giuffrè Editore, 2001).

MANDRIOLI, CRISANTO (2007): Corso di diritto processuale civile, 6a edición (Trorino, Giappichelli Editore).

MARMOR, ANDREI (2014): The language of law (Oxford, Oxford University Press).

Miranda ArRatia, Patricia (2015): Hacia un Defensor de los Derechos de la Infancia para Chile (Santiago, Unicef).

Mosquera Ruiz, Mario y Maturana Miquel, CRistián (2010): Los recursos procesales (Santiago, Editorial Jurídica de Chile).

Muñoz Aranguren, Arturo (2011): "La influencia de los sesgos cognitivos en las decisiones jurisdiccionales: el factor humano. Una aproximación”, en: Indret (№ 2), pp. 1-39.

Nieto Navia, Rafael (2011): "El valor jurídico de las recomendaciones de los Comités de Derechos Humanos y el bloque de constitucionalidad", en: Revista Colombiana de Derecho Internacional (Vol. 9, № 18), pp. 155-190.

NieVA FenOLL, JORDI (2010): “Oralidad e inmediación en la prueba: luces y sombras", en: Civil Procedure Review (Vol. 1, № 2), pp. 27-42.

NUÑEz OJeDA, RAÚl (2008): “El sistema de recursos procesales en el ámbito civil”, en: Revista lus et Praxis (Vol. 14, № 1), pp. 199-224.

PALOMO, DIEGO (2010): “Apelación, doble instancia y proceso civil oral: a propósito de la reforma en trámite", en: Revista de Estudios Constitucionales (Vol. 7, № 2), pp. 501-507.

PARKES, AISLING (2013): Children and international human rights law, the right of the child to be heard (New York, Routledge).

PeCZENIK, AleKSANDer (1992): "Los principios jurídicos según Manuel Atienza y Juan Ruiz Manero", en: Doxa, Cuadernos de Filosofía Jurídica (№ 12), pp. 327-331.

PROTO PISANI, ANDREA (1996): Lezioni di diritto processuale civile, segunda edición (Napoli, Jovene Editore).

RavetLlat Ballesté, IsAac (2017): "El Defensor de los Derechos de la Niñez en Chile: hacia un verdadero garante de su interés superior", en: Revista de Estudios Constitucionales (Vol. 15, № 1), pp. 255-306. 
RavetLlat Ballesté, IsAaC y Contreras Rojas, CRIStian (2019): "Protocolo Facultativo de la Convención sobre los Derechos del Niño relativo a un procedimiento de comunicaciones. Estudio a la luz de su aplicabilidad", en: Revista de Estudios Constitucionales (Vol. 17, № 2), pp. 225-264.

RavetLlat Ballesté, IsAac y Pinochet Olave, Ruperto (2015): “El interés superior del niño en el marco de la convención internacional sobre los derechos del niño y su configuración en el derecho civil chileno", en: Revista Chilena de Derecho (Vol. 43, № 3), pp. 903-934.

RICCI, GIAN Franco (1998): Principi di diritto processuale generale, 2a edición (Torino, Editorial Giappichelli Editore).

Romero Seguel, Alejandro (2013): El recurso de casación en el fondo civil. Propuestas para la generación de precedentes judiciales (Santiago, Editorial Thomson Reuters).

Ross, Alf (2005): Sobre el derecho y la justicia, 3a edición (Buenos Aires, Editorial Eudeba).

SÁnChez EZnARRIAGA, ZARRAluqui (2011): "El menor en los procesos de familia", en: Alcón Yustas, Fuencisla y De Montalvo, Federico (Coords.), Los menores en el proceso judicial (Madrid, Editorial Tecnos), pp. 59-81.

SAVOURY, CAROLYN (2013): "A voice for "the small": Judicial "meetings" in custody and access disputes", en: Canadian Journal of Family Law (Vol. 28, № 2), pp. 1-19.

SCHAUER, FREDERICK (1991): Playing by the rules (Oxford, Clarendon Law Series).

SolUm, LAWRENCE (2004): "Procedural Justice", en: Southern California Law Review (Vol. 78, № 1), pp. 181-321.

STEIN, FRIEDICH (1999): El conocimiento privado del juez, 2a edición (Traducc. Javier de la Oliva Santos, Bogotá, Editorial Temis).

TARUfFo, MiChele (2002): Sui confini. Scritti sulla giustizia civile (Bologna, Il Mulino). (2011): La prueba de los hechos, 4ae edición (Madrid, Editorial Trotta).

TOMASSEO, FERRUCCIO (2000): Appunti di diritto processuale civile, Nozioni introdutive (Torino, Giappichelli Editore).

TVERSKY, AMOS Y KAHNEMAN, DANIEL (1974): “Judgment under uncertainty: Heuristics and Biases", en: Science (Vol. 185, № 4157), pp. 1124-1131.

Vargas Pavez, Macarena y Correa Camus, Paula (2011): "La voz de los niños en la justicia de familia", en: Revista lus et Praxis (Vol.17, № 1), pp. 177-204.

\section{JURISPRUDENCIA CITADA}

GÓmez CON THIBAUt (2009): Cuarto Juzgado de Familia de Santiago 20 de noviembre de 2009 (acción de alimentos), en: http://www.familia.pjud/SITFAWEB/InicioAplicacion.do.

AlARCón CON ABURTo (2012): Corte de Apelaciones de Valparaíso 8 de noviembre de 2012 (acción de divorcio), en: https://bit.ly/3uHDOgq.

PONCE CON FloRes (2013): Corte de Apelaciones de Valparaíso 9 de diciembre de 2013 (acción de divorcio), en: https://bit.ly/3uHDOgq.

MoRAles CON De SOUZA (2013): Corte de Apelaciones de Valdivia 19 de diciembre de 2013 (acción de cuidado personal), en: https://bit.ly/3uHDOgq.

SEPÚlVEDA CON CÁCERES (2015): Corte de Apelaciones de Valparaíso 29 de octubre 2015 (acción de cuidado personal), en: https://bit.ly/3uHDOgq. 
PONCE CON GonzÁLEZ (2017): Corte de Apelaciones de Santiago 22 de mayo de 2017 (acción de cuidado personal), en: https://bit.ly/3uHDOgq.

Villagra CON PONCE (2017): Corte de Apelaciones de Santiago 24 de mayo de 2017 (acción de cuidado personal), en: https://bit.ly/3uHDOgq.

AgUileRA CON SEPÚlVeda (2019): Corte de Apelaciones de Santiago 4 de febrero de 2019 (acción de relación directa y regular), en: https://bit.ly/3uHDOgq.

ESPINOZA CON DELGADO (2019): Corte de Apelaciones de Valparaíso 18 de febrero de 2019 (acción de cuidado personal), en: https://bit.ly/3uHDOgq.

AltAMIRANO CON CORTÉs (2019): Corte de Apelaciones de Coyhaique 22 de marzo de 2019 (acción de cuidado personal), en: https://bit.ly/3uHDOgq.

QUIROZ CON PINO (2019): Corte de Apelaciones de Valdivia de 22 de abril 2019 (acción de cuidado personal), en: https://bit.ly/3uHDOgq.

Meriño con Avello (2019): Corte de Apelaciones de Concepción 5 de septiembre 2019 (acción de cuidado personal), en: https://bit.ly/3uHDOgq.

CÁCeres CON DROGuetT (2020): Corte de Apelaciones de Concepción 5 de junio de 2020 (acción de cuidado personal), en: https://bit.ly/3uHDOgq.

\section{NORMAS JURÍDICAS CITADAS}

ACTA 237-2014, auto acordado que regula la implementación de las salas Gesell. 30 de diciembre de 2014.

Constitución Política de la República de ChILE. Diario Oficial, 24 de octubre de 1980.

CONVENCIÓn AMERICANA SOBRE DeRECHOS HumANOS. 18 de julio de 1978.

Código ORgánico de TRIBUnAles CHILENO. Diario Oficial, 15 de junio de 1943.

CONVENCIÓN SOBRE LOS DERECHOS DEL NIÑO. Nueva York, 20 de noviembre de 1989.

Ley № 19.968, CREA los TRIBUnAles de FAmiLIA. Diario Oficial, 30 de agosto de 2004.

Ley № 21.067, CREA la Defensoría de los DeRECHOS DE LA NiÑEz. Diario Oficial, 29 de enero de 2018.

PACto InTernacional de DeReChos CiVILES y Políticos. 16 de diciembre de 1996. 